\title{
EDITORIAL
}

\section{Sleep, Oh Sleep, Where Art Thou?}

\author{
Ravi Gupta ${ }^{1}$ (1) Seithikurippu R. Pandi-Perumal ${ }^{2}$ (B)
}

Published online: 4 June 2018

(c) Springer Nature Singapore Pte Ltd. 2018

This issue of the journal contains an article that discussed the dismal state of education regarding sleep disorders in medical curriculum [1]. Authors report that despite having some information regarding the clinical presentation of obstructive sleep apnea (OSA), students were not able to deduce its clinical importance [1]. This information is important in light of the evidence that shows that obesity is a global epidemic, increasing especially among minority population in the USA and in developing countries [2]. Data from some states in India show that nearly one-third of the population is obese [3].

Obesity has been found to be associated with hosts of illnesses such as hypertension, diabetes mellitus, metabolic syndrome as well as obstructive sleep apnea $[2,4,5]$. There is a possibility that obesity mediates its metabolic and cardiovascular effects through obstructive sleep apnea. For example, metabolic syndrome was found to be twice more prevalent among obese subjects with OSA in contrast to rather than subjects with comparable body mass index, but without OSA [6]. It is important to note that the average body mass index in both groups fell within the range of morbid obesity. Molecular mechanisms leading to the development of diabetes mellitus in subjects with sleep fragmentation and intermittent hypoxemia that is seen during obstructive sleep apnea have been discovered [7]. Furthermore, Spannella et al. [8] reported that treatment of obstructive sleep apnea improved not only blood pressure, but also the metabolic profile without any change in weight. Obstructive sleep apnea also increases the predisposition to stroke; and the treatment of obstructive sleep apnea has also been found to reduce chances of future stroke [9]. Thus, there is ample evidence that obesity increases the risk for obstructive sleep apnea, which in turn increases the risk for diabetes

Ravi Gupta

sleepdoc.ravi@gmail.com

1 Department of Psychiatry, All India Institute of Medical Sciences, Veerbhadra Marg, Rishikesh 249203, India

2 Somnogen Canada Inc, College Street, Toronto, ON, Canada mellitus, dyslipidemia, cardiovascular and cerebrovascular morbidity and effective treatment of OSA improves these consequences.

Prevalence of obstructive sleep apnea in India is surprising; nearly $10 \%$ of children suffer from obstructive sleep apnea in India, and prevalence increases further among adults $[10,11]$.

Obstructive sleep apnea is not the only sleep disorder that has adverse health consequences. Insomnia with the prevalence of around $10 \%$ and sleep deprivation, for which prevalence is unknown, are other problems with which the society is struggling [12]. Insomnia and sleep deprivation adversely affect health, both in short-term as well as long-term. Like obstructive sleep apnea, these conditions also adversely affect cardiovascular health, disrupt immunity, metabolism, and glycemic control [12]. Restless legs syndrome, has been found to be present in nearly $2 \%$ of the Indian population at low altitude with nearly six times increased prevalence at moderately high altitude [13]. Restless legs syndrome is known to disrupt sleep, worsen daytime functioning, and have adverse effect on cardiovascular health [14].

In addition to adverse health consequences, sleep deprivation and disruption due to poor sleep habits and sleep disorders, respectively, have deleterious socio-economic consequences. Worsening of cognition and mood, increased proneness to accidents, absenteeism, poor productivity and consequently increased healthcare utilization is well-known in this population [15].

The country of India has nearly one-fifth of the global population. Sleep disorders becomes medically and economically important when we consider the absolute numbers of Indian population that are affected by various sleep disorders and sleep-disturbances. In absolute numbers, nearly 100 million Indians suffer from obstructive sleep apnea, a similar number from insomnia and nearly 20 million from restless legs syndrome. As already mentioned, these people are at a higher risk for metabolic syndrome, cardiovascular and psychiatric morbidities in addition to other socio-economic consequences of sleep disorders. Considering these figures, it is not surprising that India has become the world capital for 
diabetes, metabolic syndrome, and cardiovascular disorders. More importantly, as already discussed these consequences may be at least reduced, if not totally prevented by adopting strategies to reduce sleep deprivation and timely recognition and optimal management of sleep disorders.

Handling this situation requires a multipronged approach. It includes imparting knowledge of sleep disorders in public and among health professionals, strengthening and/or advancing existing medical facilities to provide optimal medical care to these patients, recognition of sleep medicine as a specialization by the national agencies that accredit medical courses, and last, investing in the research.

Prevention is always better than cure and knowledge plays an important role in preventing the development of a disorder. To focus on preventive care, knowledge has to be imparted among masses. First, education related to sleep hygiene and good sleep practices has to be included in curriculum at the school level, considering increasing sleep deprivation even among kids [16]. Second, teachers should be educated to recognize sleep problems among children and motivate their parents to seek medical help. Teachers can utilize parent-teacher meetings and other social gatherings as an opportunity to sensitize parents with regards to health issues of children. Basics of sleep, sleep loss and sleep deprivation, and how teachers as stakeholders could help to improve the sleep of children could be included in the training curriculum for schoolteachers.

The task of creating awareness among public may be quite challenging and must be undertaken by sleep specialists themselves and professional organizations related to sleep medicine. As far as the professional organizations are concerned, they are playing their role with diligence [17]. Knowledge may also be imparted by including sleep educations in the state-run preventive healthcare programs. These programs are usually designed to benefit even the last and marginalized person of the society and thus, they have widespread impact. The gap in the diagnosis and management of sleep disorders may be addressed by including sleep medicine in the undergraduate curriculum where at least three most important sleep disorders may be addressed [1]. Postgraduate training especially in certain specialties such as the internal medicine, pulmonology, psychiatry, and neurology must devote sufficient time to impart knowledge regarding sleep disorders.

Many hospitals now have a sleep laboratory and are providing clinical care. However, in most places in the Asian region, medical care for sleep disorders is provided by a single physician and there is a dearth of multidisciplinary teams that can provide optimal care. Teaching hospitals may take an initiative and be the torch-bearer for other medical facilities in the area.

Sleep medicine is a specialized area requiring knowledge and skills. Because of these reasons, in developed countries, professional medical boards recognize it as a specialty, which is opted after the residency programs in internal medicine, pulmonology, psychiatry, and neurology. However, the situation in Asian countries is grim and many medical councils still do not recognize sleep medicine as an area for specialization. There is a need for office-bearers of the medical councils to be apprised of these issues.

At last, population across the globe is diverse. For example, genetic, phenotypic, economical, cultural, and geographical diversity is often noted. These differences play an important role in the regulation of sleep and in the emergence of sleep disorders. Hence, investment in the local research is required and needs to be promoted. Various funding agencies have to address this issue.

In conclusion, as observed in many other countries, sleep medicine is fast growing, yet a nascent medical discipline in the Asian region. While major strides have been taken in several other countries to tackle this issue, in India, such initiatives are still needed. For example, developing and establishing such comprehensive services towards diagnosis and management of sleep disorders must be instituted. Considering a huge socio-economical problem like sleep disorders, it is an utmost priority to take steps towards prevention as well as management of sleep disorders in the Indian subcontinent.

\section{References}

1. Goyal A, Aswin P, Pakhare AP, Sleep Vigilance. Poor knowledge and attitude regarding obstructive sleep apnea (OSA) among medical students in india: a call for MBBS curriculum change. Sleep Vigilance. 2017. https://doi.org/10.1007/s41782-017-0028-3.

2. Imes CC, Burke LE. The obesity epidemic: the USA as a cautionary tale for the rest of the world. Curr Epidemiol Rep. 2014;1:82. https://doi.org/10.1007/s40471-014-0012-6.

3. Karla S, Unnikrishnan AG. Obesity in India: the weight of the nation. J Med Nutri Nutraceut. 2012;1:37-41. https://doi, org/10.4103/2278-019x.94634.

4. Nguyen T, Lau DC. The obesity epidemic and its impact on hypertension. Can J Cardiol. 2012;28(3):326-33. https://doi. org/10.1016/j.cjca.2012.01.001.

5. Jehan S, Zizi F, Pandi-Perumal SR, Wall S, Auguste E, Myers AK, Jean-Louis G, McFarlane SI. Obstructive sleep apnea and obesity: implications for public health. Sleep Med Disord. 2017;1(4). PMID: 29517065.

6. Seetho IW, Ramírez-Torres A, Albalat A, Mullen W, Mischak H, Parker RJ, Craig S, Duffy N, Hardy KJ, Burniston JG, Wilding JP. Urinary proteomic profiling in severe obesity and obstructive sleep apnoea with CPAP treatment. Sleep Sci. 2015;8(2):58-67. https://doi.org/10.1016/j.slsci.2015.06.004.

7. Briançon-Marjollet A, Weiszenstein M, Henri M, Thomas A, Godin-Ribuot D, Polak J. The impact of sleep disorders on glucose metabolism: endocrine and molecular mechanisms. Diabetol Metab Syndr. 2015;7:25. https://doi.org/10.1186/s1309 8-015-0018-3.

8. Spannella F, Giulietti F, Di Pentima C, Lombardi FE, Borioni E, Sarzani R. Blood pressure and metabolic changes after 3-month CPAP therapy in a very elderly obese with severe obstructive sleep apnea: a case report and review of the literature. High 
Blood Press Cardiovasc Prev. 2017;24(3):341-346. https://doi. org/10.1007/s40292-017-0190-7.

9. Gupta A, Shukla G, Afsar M, Poornima S, Pandey RM, Goyal V, Srivastava A, Vibha D, Behari M. Role of positive airway pressure therapy for obstructive sleep apnea in patients with stroke: a randomized controlled trial. J Clin Sleep Med. 2018. https://doi. org/10.5664/jcsm.7034.

10. Goyal A, Pakhare AP, Bhatt GC, Choudhary B, Patil R. Association of pediatric obstructive sleep apnea with poor academic performance: a school-based study from India. Lung India. 2018;35(2):132-136. https://doi.org/10.4103/lungindia.lungi ndia_218_17.

11. Sharma SK, Ahluwalia G. Epidemiology of adult obstructive sleep apnea syndrome in India. Ind J Med Res. 2010;131:171-5. PMID: 20308742.

12. Medic G, Wille M, Hemels ME. Short- and long-term health consequences of sleep disruption. Nat Sci Sleep. 2017;9:151-61. https://doi.org/10.2147/NSS.S134864.

13. Gupta R, Ulfberg J, Allen RP, Goel D. High prevalence of restless legs syndrome/Willis Ekbom Disease (RLS/WED) among people living at high altitude in the Indian Himalaya. Sleep Med. 2017;35:7-11. https://doi.org/10.1016/j.sleep.2017.02.031.

14. Stevens MS. Restless legs syndrome/Willis-Ekbom disease morbidity: burden, quality of life, cardiovascular aspects, and sleep. Sleep medicine clinics. 2015;10(3):369-73. https://doi. org/10.1016/j.jsmc.2015.05.017.

15. Kreiger AC (ed). In: Social and economic dimensions of sleep disorders. Sleep Medicine Clinics, 2017. Elsevier. eBook ISBN: 9780323510066; Hardcover ISBN: 9780323509879.

16. Zhang M, Tillman DA, An SA. Global prevalence of sleep deprivation in students and heavy media use. Educ Inf Technol. 2017;22(1):239-54. Print ISSN: 1360-2357; Online ISSN: 15737608. https://doi.org/10.1007/s10639-015-9440-2.

17. Kumar VM, Mallick HN, Shrivastava D. The History of Indian Society for Sleep Research (ISSR) from its inception to the launching of the journal "Sleep and Vigilance". Sleep Vigil. 2017;1:3. https://doi.org/10.1007/s41782-016-0002-5. 